\title{
Syntactic recursion and theory-of-mind reasoning in agrammatic aphasia
}

\author{
Zoltán Bánréti, Éva Mészáros \\ Research Institute for Linguistics, Budapest, Hungary \\ https://doi.org/10.36505/ExLing-2011/04/0004/000173
}

\begin{abstract}
This study investigates how aphasic impairment impinges on recursivity of language and theory-of-mind inferences. Results of linguistic tests showed that in Broca's aphasia syntactic recursion is substituted for theory-of-mind inferences on the base that linguistic system and theory- of- mind type reasoning interact with one recursion modul in human mind.
\end{abstract}

Key words: syntactic recursion, theory of mind, aphasia

\section{Introduction}

We focussed on empirical investigations involving linguistic tests administered to subjects with agrammatic and Wernicke's aphasia. The test sessions involved 5 aphasics, 3 Broca's, 2 Wernicke' aphasics as well as 21 healthy control subjects. All aphasic participants had a left unilateral brain lesion. Aphasic subjects were assigned to aphasia types on the basis of CT and Western Aphasia Battery (WAB) tests c.f. Kertesz (1982).

\section{Methodology}

Photographs representing situations of everyday life were presented to subjects and questions were asked about them. We used 208 photographs (Stark, 1998) for each test, administered in three sessions. Within the same session, no picture was involved in more than a single question type. The types of questions involved were as follows:

Type 1: What is $X$ doing in the picture? The question does not require that any of its own constituents should be involved in the structure of the answer. Type 2: What does X hate / like / want /... every afternoon / in her office etc.? The answer should be structurally linked to the question and involve: (i) a subordinate clause in direct object role, introduced by a recursive operation and signaled by a subordinating conjunction, or (ii) the verb of the question and its infinitival direct object, or (iii) a definite noun phrase in the accusative. Type 3: What can be the most entertaining/unpleasant/urgent thing for $X$ to $d o$ ? The answer should be structurally linked to the question and involve: (i) a subordinate clause in subject role, introduced by a recursive operation and signaled by a subordinating conjunction, or (ii) a bare infinitive subject, or (iii) a definite noun phrase in the nominative. Type 4: What can $X$ say / think / remind $Y$ of / ask $Y$ to do etc.? The

ExLing 2011: Proceedings of 4th Tutorial and Research Workshop on Experimental Linguistics, 25-27 May, Paris, France 
structurally linked answer must be a clause embedded introduced by a recursive operation and signaled by a subordinating conjunction.

Type 1 questions did not restrict the structure of the answer in any way. Type 2 and Type 3 questions allowed for recursive and non-recursive answers alike. Finally, Type 4 questions could only be answered in a structurally linked way by using an embedded clause, introduced recursively. The most important results of the linguistic tests can be summarised as follows.

\section{Results}

Answers given by the five aphasic subjects and ten control subjects have been classified in terms of whether (i) they were structurally linked to the questions and were or were not grammatical; or (ii) they were not structurally linked to the questions and were or were not grammatical.

Table 1. The ratio of structurally linked answers to all answers is given within the brackets; the percentage of grammatical answers is given outside the brackets.

\begin{tabular}{|c|c|c|c|}
\hline Subjects & $\begin{array}{c}\text { Wernicke's aphasics } \\
2\end{array}$ & $\begin{array}{c}\text { Broca's aphasics } \\
\mathbf{3}\end{array}$ & $\begin{array}{c}\text { Normal control } \\
21\end{array}$ \\
\hline $\begin{array}{l}\text { Type } 1 \text { question } \\
\text { Number of answers: }\end{array}$ & $\begin{array}{c}(68.8) \underline{50.8} \\
107\end{array}$ & $\begin{array}{c}\text { (56.3) } \underline{45.6} \\
257\end{array}$ & $\begin{array}{c}(100.0) \underline{100.0} \\
1117\end{array}$ \\
\hline $\begin{array}{l}\text { Type } 2 \text { question } \\
\text { Number of answers: }\end{array}$ & $\begin{array}{l}(46.0) \underline{40.3} \\
111\end{array}$ & $\frac{(37.1)}{246}$ & $\begin{array}{c}(100) \underline{99.1} \\
1115\end{array}$ \\
\hline $\begin{array}{l}\text { Type } 3 \text { question } \\
\text { Number of answers: }\end{array}$ & $\begin{array}{c}(60.4) \underline{34.3} \\
120\end{array}$ & $\begin{array}{c}(30.8) \underline{22.8} \\
240\end{array}$ & $\begin{array}{c}(100) \underline{98.5} \\
1139\end{array}$ \\
\hline $\begin{array}{l}\text { Type } 4 \text { question } \\
\text { Number of answers: }\end{array}$ & (66.7) $\underset{76}{61.1}$ & $\begin{array}{c}(60.3) \underline{45.6} \\
218\end{array}$ & $\begin{array}{c}(100.0) \underline{100.0} \\
982\end{array}$ \\
\hline
\end{tabular}

According to Table 1 the number of structurally linked and grammatical answers decreased from Type 1to Types 2 and Types 3 . With respect to Type 4 questions (What does $X$ say / think / remind $Y$ of / ask $Y$ to do?), requiring a recursively embedded clause as an answer, the performance of the subjects actually turned out to be better than with Type 1 questions (What is $X$ doing?); or it was almost as good.

With respect to Type 4 questions Wernicke's aphasics produced some conjunction-initial clauses and some clauses involving the subjunctive (i.e., the mood directly indicating subordination). Broca's aphasics gave few 
Syntactic recursion and 'theory of mind' reasoning in agrammatic aphasia 21

answers beginning with a subordinating conjunction. The majority of structurally linked and grammatical answers produced by Broca's aphasics, as well as the rest of the answers given by Wernicke's aphasics, were statements that assumed the point of view of one of the characters seen in the picture, rather than being purely descriptive. The subjects answered the question as if they were in the "mental state" of the characters. These answers are referred to as "situational statements" with 'theory-of-mind' type reasoning. In them, the verb was inflected in the first, rather than the third, person singular. They directly represented the thought or statement of the characters they "cited". Most of them did not involve a subordinating conjunction. An example for situational statement:

The picture: A girl is showing her scar to a boy.

Question: Vajon mire gondol a fiu'? 'What may the boy be thinking of?"

S.T.'s answer: Mindjárt rosszul leszek! 'I'm going to be sick'.

Possible recursive construction: Arra gondol, hogy mindjárt rosszul lesz.

'He thinks he is going to be sick.'

Table 2. The share of situational statements in answers to Type 4 questions:

\begin{tabular}{|c|c|c|c|}
\hline Subjects & $\begin{array}{l}\text { Wernicke's aphasics } \\
\text { (answers :76) }\end{array}$ & $\begin{array}{l}\text { Broca's aphasics } \\
\text { (answers: 218) }\end{array}$ & $\begin{array}{l}\text { Normal control } \\
\text { (answers: 982) }\end{array}$ \\
\hline Situational statement & (43.3) $\underline{43.3}$ & (74.0) $\underline{60.3}$ & (31.0) $\underline{\text { 31.0 }}$ \\
\hline $\begin{array}{l}\text { Sentence with } \\
\text { subjunctive mood }\end{array}$ & (14.2) 14.2 & (10.0) $\underline{10.0}$ & -- \\
\hline $\begin{array}{l}\text { Subordinating conjunction } \\
+ \text { situational statement }\end{array}$ & (12.5) $\underline{12.5}$ & (14.5) $\underline{8.7}$ & (24.0) $\underline{24.0}$ \\
\hline $\begin{array}{l}\text { Subordinating conjunction } \\
+ \text { descriptive clause }\end{array}$ & (30.0) $\underline{\text { 30.0 }}$ & (1.4) $\underline{1.4}$ & (45.0) $\underline{45.0}$ \\
\hline
\end{tabular}

\section{Discussion}

The majority of Broca's aphasics' answers to Type 4 questions were simple situational statements containing theory-of-mind type reasoning without subordinating conjunctions. The low percentage of subordinating conjunction in Boca's aphasic's answers shows that syntactic structural recursion is impaired.

In the sense of Takano - Arita (2010) theory-of-mind type reasoning is recursive. Agrammatic Broca's aphasics may use recursive theory-of-mind inferences (and situative sentences carrying them) in their responses as a repair/compensatory strategy in order to avoid syntactic-structural recursion. 
The content of situational statements showed that Broca's aphasic subjects correctly identified themselves with the mental states of the characters in the pictures, c.f. Siegel - Varley - Want (2006).

The use of simple situative statements could also be observed in the case Acknowledgements of control subjects, but only in $31 \%$ of their responses.

The share of situational statements jumped up in Broca's answers to Type 4 questions. A subset of linguistic devices indicating non-descriptive perspective was available for subjects, c.f.: theory-of -mind statements were based on a very simple syntax, verbs inflected with the first person singular feature. The complex linguistic subsystem of syntactic recursion was partially available or was not available at all for aphasics. Syntactic structural recursion was substituted for theory-of-mind recursion on the base that syntax and social cognition system interact with one common recursion modul.

\section{Conlcusion}

Findings support a model that posits a recursion module in the human mind that is shared by linguistic and theory-of-mind performance. In agrammatic aphasia syntactic representations are disconnected from the recursion modul but theory-of-mind type reasoning can access to the recursion modul.

\section{Acknowledgements}

This research has been supported by the National Scientific Research Fund (OTKA), project: NK 72461.

\section{References}

Kertesz, A. 1982. The Western Aphasia Battery. New York, Grune \& Stratton.

Siegal, M., Varley, R., Want, S.C. 2006. Mind Over Grammar. Reasoning in Aphasia and Developmental Contexts. In Antonietti, A., Liverta-Sempio, O., Marchettio, A. (eds), Theory of mind and language in developmental contexts, New York, Springer, 107- 119.

Takano, M., Arita, T. 2010. Asymmetry between Even and Odd Levels of Recursion in a Theory of Mind, in: Proceedings of ALife X, ed.: L.M. Rocha, L.S. Yaeger, M.A. Bedau, D. Floreano, R.L. Goldstone, $\underline{\text { A. Vespignani }}$ http://www.citeulike.org/user/jasonn/article/7293338 